\title{
Planning for the regeneration of towns and cities
}

\author{
Claudio de Magalhães and Nikos Karadimitriou
}

$[6,211$ words]

\section{Introduction}

Defining what 'urban regeneration' is and what interventions and policies that term encompasses is not straightforward. The term has been applied equally to any significant redevelopment of rundown urban sites, as well as to complex sets of strategies to tackle structural social and economic urban problems. As with most practice-based policy fields, the definition of what 'urban regeneration' is, has been built over the years, as understandings of what the urban problems that need regeneration solutions are, have evolved and changed.

Gripaios (2002) suggests that urban regeneration problems could be classified roughly in two categories. The first comprises deteriorated areas within otherwise relatively prosperous cities, whose economy and population have persistently failed to benefit from the surrounding prosperity. The second encompasses those cities and areas of cities situated in regions with a depressed economy, which require interventions that go well beyond the locality and the city.

However, defined, a constant element in urban regeneration interventions is the use of large-scale changes in the built environment through re-development operations, as a way of revitalising the local economy and changing the dynamics of social relations in a locality. If in the past those large-scale redevelopment projects were led and funded by the public sector as part of state-led comprehensive strategies, they have become dependent upon private initiative, private funding and the dynamics of real estate markets for the delivery of the social and economic policy goals expected from them. Moreover, as discussed in Chapter 1, that private 
initiative and funding are increasingly global in nature, creating a complex link between localities and global flows of capital.

This chapter focuses on the built environment dimension of urban regeneration - where planning is of paramount importance - and looks at the challenges facing practice. The first part examines the concept of urban regeneration, and looks at the role property development has assumed in it. Urban regeneration has evolved as a policy field concerned with solving localised social and economic problems, mostly through changes in the built environment. From the 1980s, those changes have increasingly taken the form of privateled property development projects. Emblematic of that are the large private-led but state-supported flagship projects such as Canary Wharf in London, Salford Quays in greater Manchester, the Quayside in Newcastleupon-Tyne, or more recently the London Olympic Park, which were meant to redefine the economic role of their location and create the wealth that would ultimately address problems of social need and deprivation. Whether or not they have achieved this goal or were even inherently capable of doing that is still a contentious point (see Swyngedow et al 2002; Imrie et al 2009). Turok (1992) pointed out early on the limits of regeneration strategies based on an excessive reliance on property development and the weakness of the claims made in their favour. Moreover, the existing evidence is inconclusive whether regeneration programs based on physical restructuring and redevelopment have been the main determinant of long-term structural changes in the economy and social well-being of the areas where they have been applied, and whether change was in the intended direction and the benefits were received by those for whom they were meant (see Cheshire 2006; Ball and Maginn 2005; Webber et al. 2010). Nevertheless, as the involvement of the public sector in the funding and delivery of those projects recedes even further, more of the task of achieving broader policy goals is left to the property market. The nature of urban regeneration practice changes accordingly as it becomes preoccupied with configuring and influencing property markets, capturing part of the value they create and using that value for broader policy goals.

The second part of the chapter then looks at the challenges that property-led urban regeneration presents to those involved in its delivery. If urban regeneration is about addressing problems of economic decline, social 
exclusion, dereliction and lack of sustainability through physical, property-related interventions, we need to understand how physical change impacts on social and economic processes and how this can be utilised in policy delivery. Moreover, if urban regeneration interventions produce benefits that are broader than just local improvements in the built environment, how are they distributed? The reliance on property markets to deliver regeneration outcomes entails the risk that left to their own devices, markets will distribute those outcomes through price mechanisms, and more often than not, those communities regeneration seeks to benefit will be outbid by others. There is, therefore, a distributional challenge as witnessed for example in the debates around gentrification and the capture of regeneration benefits by wealthier in-comers. That reliance on markets also means that urban regeneration is, as a rule, delivered in partnerships with private actors, who have the power to fund and develop those interventions.

Balancing private and public interest is always difficult. Imbalances of power within regeneration partnerships and the sometimes conflictive nature of the interests represented in them require strong accountability mechanisms that are responsive to all those who should have a say in a regeneration intervention. Finally, as regeneration has come to depend on property markets, the issue of risk management and value capture come to the fore. Property development is a risky business, and more so if it is required to deliver public goods and other policy objectives. Ensuring successful regeneration means that the different risks facing private, public and community actors in the different stages of an intervention are managed adequately so that expectations are met and the project does not stall. Capturing the value created by those interventions and apportioning it appropriately to meet policy objectives is an essential part of the challenge. The chapter concludes this brief summary of the challenges facing urban regeneration practice with some reflections on what they mean and the implications for practitioners.

\section{Urban regeneration: a shifting concept}

The basic idea that urban areas are in need of regeneration (and not simply of redevelopment) comes from a particular understanding of the causes of the problems of economic and social decline in advanced capitalist 
cities and of the appropriate policy responses to those problems. That understanding has at its core the proposition that the economic decline of a locality, with its attending social and environmental problems, could be more effectively addressed as problems of that locality rather than as economic, social or environmental problems that happened to take place in that locality.

From its emergence as a distinct policy field in the 1970s to today, urban regeneration has come to signify that field of public policy that deals with the restoration of economic activity, the promotion of social cohesion and the re-establishment of environmental quality in localities where those elements have deteriorated (Couch and Fraser 2003).

However, this multi-dimensionality of the concept of urban regeneration begs the question of what the causal links connecting those dimensions might be, how they work and how policy could act upon them. The notion of urban regeneration is based on the assumption that economic and social problems are not a-spatial, and that the character of a location can determine the nature of those problems and compound them. Extensive areas of physical dereliction or inadequate physical infrastructure are likely to deter investment in a locality and may exacerbate downward spirals, making the spontaneous renovation far more difficult. The spatial concentration of socially disadvantaged groups might compound their problems by weakening their interactions with the rest of society, thus reinforcing patterns of social exclusion. It should be noted that some of these causal links have been assumed rather than demonstrated (see e.g. Cheshire 2006). Another element in the notion of urban regeneration is that the decline (physical, social or economic) is often of a structural nature and will not be reversed spontaneously as part of the normal process of change and adaptation that is part of the life of cities. In this case, change requires purposive action by the state through policy and direct intervention, as market forces in themselves cannot trigger and ensure adaptation or transformation and may well be causal factors of the decline itself (Jones and Evans, 2013). 
The problems addressed by urban regeneration are often described as examples of 'wicked issues' (Clarke and Stewart 1997). They are policy problems that seem intractable, persistent and not amenable to simple solutions. Moreover, they are multifaceted; their consequences span over the areas of competence of many different government agencies; they are not amenable to solutions coming from one single powerful governmental actor and they require the involvement of actors beyond government; it takes much longer than conventional programme horizons and electoral cycles for solutions to have an impact.

The multi-dimensionality of the problems addressed by urban regeneration interventions underpins the complexity of the objectives those interventions seek to achieve. These are marked by tensions, not just between different views of what a better city or city quarter might be, but also between different perceptions of the role of those different dimensions in bringing about the desired outcomes. The conflicts between physical redevelopment and environmental improvement on the one hand, and social and economic benefits on the other are well-documented (Turok 1992, Swyngedow et al 2002). Similarly, Butler and Hamnet (2009) point out to a longstanding tension between economic competitiveness, physical transformation and social inclusion.

All that complexity makes urban regeneration foremost an empirical policy field, which grapples with the complex connections between the built environment, the economy and society at different scales, and tries to intervene in processes and phenomena for which causality has not always been clearly established. Urban regeneration practice has often tried to replicate 'what works', even if it often cannot explain why it works or whether it would work in a different context.

Nevertheless, the problems of urban decline are real, they can dramatically affect the economic and social wellbeing of neighbourhoods and can put considerable pressure on governments. Because of its inherent complexity, over the nearly four decades in which urban regeneration policies have been pursued in the UK, their objectives have varied. This is not only because of the changing nature of the problems associated with 
urban decline but also because of changing understandings of how the dimensions of regeneration relate to one another and how that relationship could be mobilized towards desired aims. Changing ideological perspectives from successive governments and shifts in the balance of power of the potential beneficiaries and losers of regeneration policies have also affected regeneration programme objectives (De Magalhães 2015).

Two related elements, however, have become characteristic of regeneration practice, no matter what the aims of particular regeneration interventions might have been. The first is a close relationship between urban regeneration and property development - which has a long tradition in planning thought. The second is a reliance on public-private partnerships, which emerged in the 1980s and gained substantial ground with the dominance of New Public Management approaches to government, with its emphasis on introducing private sector management practices into the running of the state (Leach and Percy-Smith (2001).

After an early period where the focus was on property development for its own 'virtues' of employment creation and economic multiplier effects (see Turok 1992 or Swyingedow et al 2002 for early critiques), the key focus of such policies eventually shifted towards a more complex treatment of the built environment. This includes the creation of mixed communities in terms of income and tenure, the return of middle class households to the city and the introduction of mixed-use developments in formerly single-use areas. As before, private developers and private capital were meant to play a major role in these processes.

This type of engagement with markets and the private sector means that the final combination between private and public goods of all sorts, on which the delivery of policy objectives depends, is determined by a mix of policy directives and market signals. Brandsen \& Pestoff (2006) have used the term 'co-production' to define this approach to shaping policy goals when it comes to the relationship between the state and voluntary sector organisations. That term could also describe how public sector and private sector actors engage in contemporary urban regeneration. In this field, societal goals are to be met by a process of partnership and negotiation with (and transfer of a wider range of decision-making powers to) developers, third sector providers, financial agents, and the beneficiaries and users. Therefore, in urban regeneration the 
boundaries between the state and private interests, state and civil society, between producers and users of policy are increasingly shaped by contractual relations and partnership mechanisms, which attribute rights and responsibilities in a way that makes the distinction between client and contractor, provider and user, or policy maker and policy beneficiary rather tenuous (Sullivan \& Skelcher, 2002).

This shift from a 'provider' state to an 'enabling' one (Sullivan \& Skelcher, 2002) and the move towards coproduction have not been smooth processes. Organisational forms, skill sets and routines that might have been useful under one governance mode, have proven to be inadequate under the other. For the public sector, the restructuring that has accompanied that shift is well documented (see Anderson \& van Kempen, 2001; Stoker, 2004; Leach \& Percy-Smith, 2001; Stewart \& Walsh, 1992).

Similarly, private sector players in regeneration have had to adapt their business strategies to take into account the introduction of a multiplicity of new policy objectives into their business environment (Karadimitriou, 2005). Policy objectives have been factored in property development for quite a while. However, in more recent times an increasingly complex set of societal objectives is being required from private developments, well beyond those implicit or explicit in land use planning and related policies. For example, the delivery of affordable housing, of forms of mixed-use and mixed-tenure, an attractive public realm, local employment initiatives, amenities and social facilities are now almost standard requirements in private-led and funded large development projects in the UK. Planning gain, the developers' obligations under Section 106 of the Town and Country Planning Act 1990 was originally a way to provide mitigation for the impacts of a development, but it has progressively become the main instrument of delivery of a broad array of policy objectives, especially in what concerns housing (see Burgess et al., 2011).

An important consequence of this redefinition of the relationships between state and market actors in development is that the problems of urban and regional decline and its physical consequences have often been read from the perspective of the property market (Turok, 1992; Colenutt, 1999; Adams et. al., 2005; 
MacLaran, 2003). This has affected the way these problems are perceived and defined and consequently the solutions proposed to tackle those problems. From this perspective, the consequences of the decline of a locality suffering from the loss of economic activity - including the existence of run down houses, derelict buildings and vacant spaces - can be interpreted as a problem with land and property prices in that area, associated with falling demand for that location. The assumption that a healthy property market is a precondition for economic and social regeneration has affected urban policy and regeneration initiatives since the 1980s (see Turok, 1992).

Under this light, the problems of declining urban areas are often recast as related to a lack of demand in the property market. This lack of demand would mean that no private investment would come forward to provide the new or refurbished spaces that could attract and accommodate more dynamic economic activities or the housing and amenities for the labour force coming to serve them. Making available the 'right' kind of public and private goods like commercial buildings, parks, facilities, homes and infrastructure would therefore be an important element in attracting those businesses and an adequate pool of labour, provided that other economic, social and institutional parameters were favourable.

\section{<insert Figure 17.1>}

Figure 17.1: The Olympic Village in London, regeneration through property development. The built environment outcomes are clear, but how can it produce the desired social outcomes?

(Source: EG Focus CC BY 2.0)

There has been a long debate as to what the relationship between a dynamic property market and a growing economy and prosperous society is (Turok, 1992; Adams et. Al., 2005) and the current consensus is that the relationship is more complex than one of constant unidirectional causality between property investment and economic development. However, few deny the importance of investment in the built environment in reversing declining urban areas. In a context in which a large part of this investment has had to come from actors other than the state, the problem and its solutions have been formulated, at least in part, in terms of property markets and their functioning. 
According to this logic therefore, in order to achieve such objectives, policies are needed to restore the function of the property market in problem areas, which in the long-run will secure their regeneration. Thus, various constraints to development have been identified in the form of e.g. fragmented landownership, costs of land decontamination, poor transport access, lack of adequate infrastructure, costs of and access to development finance, lack of confidence and excessive risks, uncertainties and low profitability (Jeffrey \& Pounder, 2000; Syms, 2002; Adair et. Al., 2003). State involvement aiming at securing the provision of buildings and infrastructure is largely predicated on the premise that these constraints have to be lifted. Moreover, given the significant household investment function of homeownership, increasing dwelling prices often create a substantial 'wealth effect' whereas lack of demand and falling prices inevitably lead to a decrease in the price of many households' most important asset, their homes, affecting their mobility and consumption (Barker, 2004; Gregory, 2011). Saddled with mortgages for homes whose price drops significantly, homeowners can be trapped in increasingly more derelict locations where dropping consumption creates self-reinforcing spirals of decline (Nevin \& Leather, 2006). Thus, securing a buoyant housing market has beeen seen as important for public policy. This rationale underpinned governmentfunded regeneration programmes tackling housing market weakness through supply-side measures such as selective demolition, stock transfers, refurbishment and reconstruction in order to establish and inflate a housing market (Nevin \& Leather, 2006). This perhaps oversimplistic veiw of the role of housing markets in regeneration has began to change only very recently with the crisis of housing affordability, especially acute in London and the South East of England. An excessively buoyant housing market can be as much of an urban regeneration problem as a stagnant or declining one.

What the paragraphs above try to do is to describe what urban regeneration in the UK has become: a way of addressing issues of decline, social exclusion and a host of other public policy objectives through private-led property development operations, which are expected to provide the spaces, the public goods and the kind of built environment that will turn those policy objectives into reality. This, of course, presents several challenges to practitioners, which are discussed in the next section. 


\section{The challenges for practice}

From the discussion above, it is clear that urban regeneration is about more than just ensuring that the redevelopment of derelict areas results in places that are liveable, environmentally sustainable and of high design quality. That is very important, but what makes a redevelopment 'regeneration' is that it should also help to deliver a series of social and economic policy goals as well as places that are liveable and sustainable. Employment, economic growth, affordable housing, poverty, social exclusion, education, skills, etc. are all potential target areas of urban regeneration, to be acted upon with the help of built environment interventions. Because of that, although the remit of urban regeneration is in a sense wider than that of planning, it is still essential to engage with planning as a policy field in which decisions about the built environment are taken, which ultimately will or will not deliver all other policy objectives.

However, as suggested above, those regeneration targets are to be delivered primarily through privatelyfunded and privately-led property development interventions, which are structured around profitability and financial viability. In the past, public sector subsidies in various forms ensured the desired balance between profitability and the delivery of non-profitable policy objectives (public spaces, affordable housing, schools, health facilities, training, etc.). Over the years, however, and especially with reductions in public spending that preceded but were made more drastic in the wake of the 2007 financial crisis, subsidies and public investment have dwindled. Securing broader regeneration objectives have become increasingly dependent on the ability of governments - national and local - to influence the workings of property markets through regulating it and trying to reshape the decision-making context of market players or the factors that determine profitability and viability (see Adams and Tiesdell 2010 for a discussion on the relationship between planning and markets). 
As mentioned earlier, partnerships of all sorts have been used to try and bring public, private and occasionally community actors together to try and align interests and shape the context for outcomes. In the recent past, instruments such as Urban Development Corporations created the framework for a partnership between the public sector, local authorities and - albeit belatedly - communities. Today, apart from the two Mayoral Development Corporations in London, ad-hoc partnership arrangements prevail. In some cases, local authorities have used their ownership of land to influence the outcomes of developments and secure public goods and other policy objectives. In others, the use of regulatory powers has been the main instrument to secure those outcomes: Compare, for instance, the regeneration of New Islington in Manchester, where the City Council was a major landowner and used their holdings to secure large public spaces and social facilities, and Kings Cross in London, where pubic land was residual and public goods had to be negotiated in a protracted planning permission application. Or, the controversial regeneration of the Heygate social housing estate in London, in which local authority landownership does not seem to have been used to its full potential apart from facilitating the hugely profitable private redevelopment (see Lees and Ferrery 2016).

\section{<insert Figure 17.2>}

Figure 17.2: The Heygate Estate in London: landownership could have given the local authority a powerful tool to shape the outcomes of the redevelopment towards the aspirations of the existing community, but many argue this has been wasted.

(Source: London SE1 Community Website CC BY 2.0)

In this context, the role of planners is different from that of proposers of urban regeneration plans, or of just arbiters of private development proposals, making sure they respond to the needs of a place in a way that meets the public interest. For that to happen, there is a need for complex arrangements in which public sector actors use their legal powers to authorise development, or their leverage as infrastructure providers or regulators, or their powers as landowners (when possible), to influence and shape the dynamics of the property market in a particular location and make sure private developers create a financially successful 
development and, at the same time, deliver the public goods and the kind of place local communities and planners want. Moreover, these arrangements need to be at once firm enough to secure public goods are delivered, but also flexible to cope with the uncertainty and cyclicality of property markets. Successful regeneration projects are those that have managed to keep all key stakeholders (developers, landowners, local authorities, communities), with their different aims and motivations, in a constant dialogue so that risks and benefits are shared in acceptable ways.

Implicit in this often uneasy combination of public, private and community actors is an effort to ensure that the different types of uncertainties and risks faced by the different actors are considered and reduced as far as possible. Urban regeneration is inherently uncertain and risky, and this includes financial and market risks for private partners, financial and political risks for public bodies and risks to their welfare for the communities involved. The delivery of goods, services and facilities like affordable housing, health, education, public spaces, etc. is therefore a key element in the negotiation between public, private and third sector actors around the apportionment of risks and rewards, and the way this is done shapes the nature of urban regeneration as public policy. Aligning the interests of all those parties requires negotiating and arranging how risks and rewards are distributed (Karadimitriou, De Magalhães and Verhage 2013, Karadimitriou and Manns 2016).

What is then the role of planning and planners in this process? This chapter discusses two main challenges associated with that role: the issue of how to ensure that what is primarily a private development operation produces public goods and social and economic policy goals, and that of ensuring that the necessary negotiations that lead to development outcomes are as transparent and accountable as possible.

The traditional planning instruments such as local plans and local area plans certainly play a part here, by setting the outlines of a vision for areas that can be regenerated through redevelopment. However, achieving regeneration outcomes relies on extracting all sorts of public goods and social and economic benefits from 
private-led development operations, some which might come as a natural consequence of development itself (e.g. a renewed built environment, active land uses where previously there weren't any, valorisation of the surrounding area), but many will need to be manufactured through negotiation, imposition and bargaining. The challenge is how to capture part of the uplift in land value created by redevelopment and regeneration, the benefits and positive externalities they generate, and utilize them to pay for public goods that will benefit the intended beneficiaries of regeneration. The topic of value capture has featured high in the agenda of planers and municipal administrators worldwide, trying to find ways of devolving to society some of uplift in value generated through development, which is socially created and would otherwise be captured privately, and help fund public goods and key infrastructure (see e.g. Ingram and Hong 201, Alterman 2012). For historical reasons, UK local governments and the planning system have never had strong instruments for the capture of land value uplifts, differently from some of their European neighbours. In absence of betterment taxes, municipal land banking, pre-emption rights or intermediary public landownership, UK local authority planners have had to rely on weaker mitigating instruments such as planning obligations under Section 106 of the Town and Country Planning Act 1990, more recently on a fixed-value Community Infrastructure Levy and on time consuming negotiating and bargaining (discussed earlier in Chapter 5).

In those circumstances, planners need to have the relevant skills to allow them to understand the dynamics of development, to capture value without compromising viability, to direct the benefits to the intended recipients, to be flexible to adjust to market cyclicality, to tie the parties together, all of which are not normally part of what is typically associated with their professional profile. The private development companies involved in urban regeneration will have multidisciplinary teams with appropriate sets of skills. However, local authority planners working in urban regeneration can no longer rely on equivalent teams in their own authority, as these have more often than not been decimated by budget cuts. There is therefore an imbalance in the ability to capture development value to secure policy outcomes; how to overcome it is where the real core of the challenge lies. 
That brings forth the second of the challenges discussed in this section. The process of negotiation and bargaining required to allocate benefits and risks and secure value uplifts that are shared among private developers and communities requires complex negotiation. Occasionally, but not always, this is under the institutional umbrella of a public-private partnership, in which compromises and adaptations have to be made, both with regards to the development itself and the requirements of the local authority. Urban regeneration, as a rule, is likely to produce winners and losers. We should remember that a common critique of urban regeneration through property development projects is that its benefits are more likely to be appropriated by development interests and incoming residents than by existing residents and businesses, whereas the losses are more likely to fall to the latter (Imrie and Thomas 1993). However, in democratic societies the process whereby decisions are made about who loses and who wins matter.

The point is how the public interest and the interests of deprived communities might be protected in urban regeneration interventions. For much of the history of urban policy in representative democracies, this was seen as the natural role of the state and the public sector. However, British regeneration policy objectives have been predicated upon interventions in which the state is only one and not necessarily the dominant partner. An abundance of mechanisms have been employed, with different configurations of relative power between public and private sector actors and different levels of accountability to the communities affected. Whilst there are several examples of partnerships that have been effective in representing the interests of a wide range of stakeholders and in managing conflicts well, there are also plenty of examples of contested arrangements, in which stakeholders felt unrepresented, and which were seen as biased towards development interests to the detriment of local residents or the public interest (see Imrie et al 2009).

Again, the way different views are taken into account, the way decisions are made and the balance between different aspirations and needs is struck does matter. The challenge for urban regeneration and those involved in it, is therefore participation and accountability. More so as many decisions about the shape, timing and outcomes of urban regeneration projects are taken within public-private bodies outside the normal rules of accountability of local governments. The issue is therefore how to secure accountability and 
representativeness in partnerships and other similar governance mechanisms. Ensuring that all those with a stake in the regeneration intervention are represented and managing the conflicts that are unavoidable in that sort of policy action is key in ensuring that regeneration takes place, that it is supported and that and that the social and economic outcomes are genuine and fairly distributed. And this is no easy task.

\section{Conclusions}

This brief overview of urban regeneration describes what this field of policy is in practice, and the challenges it poses for those - planners or other professionals - in charge of delivering it. For a start, one would expect that after decades of urban regeneration policies, we would be able to offer a much more decisive account of what works and what does not, and therefore what urban regeneration should be about and how it should be operate. However, even the question whether regeneration policies and programmes themselves actually make any difference has not been settled. It may sound evasive to say 'it depends' but the truth of the matter is that the impact of any such initiatives actually does depend on contextual and other factors which often are beyond anyone's control. There are brilliant examples of regeneration initiatives that have turned entire cities around and there is an equal number of programmes which have thrown good money after bad, year upon year. Early $21^{\text {st }}$ century globalised capitalism and its ever-increasing speed of change in the social and spatial arrangements of production relationships makes it exceedingly hard for governance systems to respond to the challenges and the opportunities that are often thrust upon them.

This requires institutional arrangements that can bring together different parties with an interest in the regeneration of an area, accommodate diverse interests and negotiate conflict, and above all, be flexible to adapt to the contextual changes and the various challenges and risks those changes will bring, over the typically long run of a regeneration intervention. 
Faced with this context, planning practitioners engaging in regeneration have to develop skills which span a breadth of disciplines, and which traditionally have not been part of their education. Urban design or policy making skills are of course indispensable but not enough to deal with the multiple layers of complexity and the fuzzy nature of the process. The management of the risks inherent in this process and the sensitive nature of the negotiations about risk and return require lateral thinkers who can understand regeneration through the eyes of a wide range of actors and manage conflicting interests. Financial literacy is now required more than ever, coupled with negotiation and communication skills as well as a focus on human well-being and a strong commitment to the cause of creating liveable, sustainable communities.

\section{References}

Adair A, J Berry and S McGreal, 2003, 'Urban regeneration and property investment performance', Journal of Property Research, 20 (4), pp 371-386.

Adams D and S Tiesdell, 2010, Planners as Market Actors: Rethinking State-Market Relations in Land and Property, Planning Theory and Practice, 11 (2), pp 187-207

Adams D, C Watkins and M White (eds.), 2005, Planning, Public Policy and Property Markets, Oxford: Blackwell

Alterman R, 2012, 'Land Use Regulations and Property Values: The 'Windfalls Capture' Idea Revisited', in N Brooks, K Donaghy, and G-J Knaap (eds.), The Oxford Handbook of Urban Economics and Planning, Oxford: Oxford University Press, pp 755-786

Anderson H and R van Kempen (eds.), 2001, Governing European Cities: Social fragmentation, social exclusion and urban governance, Aldershot: Ashgate 
Ball M and P Maginn, 2005, Urban Change and Conflict: Evaluating the Role of Partnerships in Urban Regeneration in the UK, Housing Studies, Vol. 20 (1), pp 9-28

Barker K, 2004, Review of Housing Supply - Delivering Stability: Securing our Future Housing Needs Final Report, Norwich: HMSO

Brandsen T and V Pestoff, 2006, "Co-production, the Third Sector and the delivery of public services", Public Management Review, Vol.8 (4), pp 493-500

Butler T and C Hammet, 2009, Regenerating a Global City, in R Imrie, L Lees and M Raco (eds.), Regenerating London: Governance, Sustainability and Community in a Global City, Abingdon: Routledge, pp $40-57$

Burgess G, S Monk and C Whitehead, 2011, Delivering local infrastructure and affordable hous Delivering local infrastructure and affordable housing through the planning system: the future of planning obligations through S obligations through Section 106, People, Place \& Policy, Vol. 5 (1), pp1-11

Cheshire P, 2006, Resurgent Cities, Urban Myths and Policy Hubris: What We Need to Know, Urban Studies, Vol. 43 (8), pp 1231-1246

Clarke M and J Stewart, 1997, Handling the Wicked Issues: A challenge for government, Birmingham:

\section{INLOGOV}

Colenutt B, 1999, "Deal or no deal for people based regeneration?, in R Imrie and H Thomas (eds.), British urban policy: an evaluation of the urban development corporations, London: Sage, pp 233-245

Couch C and C Fraser, 2003, Introduction: The European context and theoretical framework, in C Couch, C Fraser and S Percy (eds.), Urban Regeneration in Europe, Oxford: Blackwell, pp 1-16 
De Magalhães, 2015, “Urban Regeneration”, in James D. Wright (editor-in-chief), International Encyclopaedia of the Social \& Behavioural Sciences, 2nd edition, Vol 24. Oxford: Elsevier, pp 919-925

Gregory J, 2011, Can Housing Work for Workers?, The Fabian Society Touchstone Pamphlet No. 11, London: TUC

Gripaios P, 2002, The Failure of Regeneration Policy in Britain, Regional Studies, Vol.36, pp 568-577.

Imrie R, L Lees and M Raco (eds.), 2009, Regenerating London: Governance, Sustainability and Community in a Global City, Abingdon: Routledge

Imrie R and H Thomas, 1993, The limits of property-led regeneration, Environment and Planning C:

Government and Policy, Vol.11, pp 87-102

Ingram G and Y-H Hong (eds.), 2012, Value Capture and Land Policies, Cambridge MA: Lincoln Institute of Land Policy

Jeffrey P and J Pounder, 2000, “Major Themes and Topics: Physical and Environmental Aspects”, in P

Roberts and H Sykes (eds.), Urban Regeneration: a Handbook, London: Sage, pp 86-108

Jones P and J Evans, 2013, Urban Regeneration in the UK, London: Sage

Karadimitriou N, 2005, "Changing the way UK cities are built: The shifting urban policy and the adaptation of London's housebuilders". Journal of Housing and the Built Environment, Vol. 20 (3) pp. 271-286

Karadimitriou N and Manns J, 2016, Our Common Estate: Planning for Land in Large Scale Urban Development, Journal of Urban Regeneration and Renewal Vol 9(2), pp. 139-148 
Karadimitriou N, De Magalhães, C. and Verhage, R. 2013, Planning, Risk and Property Development:

Urban Regeneration in England, France and the Netherlands, Abingdon: Routledge

Leach R and J Percy-Smith, 2001, Local Governance in Britain, Basingstoke: Palgrave

Lees L and M Ferreri, 2016, Resisting gentrification on its final frontiers: Learning from the Heygate Estate in London (1974-2013), Cities Vol 57 (September 2016), pp 14-24

MacLaran A (ed.), 2003, Making Space: Property Development and Urban Planning, London: Arnold

Nevin B and P Leather, 2006, "Understanding the drivers of housing market change in Britain's post-

industrial cities", in P Malpass and L Cairncross (eds.), Building on the Past. Visions of Housing Futures,

Bristol: The Policy Press, pp 97-126

Roberts P and H Sykes (eds.), 2000, Urban Regeneration: a Handbook, London: Sage.

Stoker G, 2004, Transforming Local Governance: From Thatcherism to New Labour, Basingstoke: Palgrave

Sullivan H and C Skelcher, 2002, Working Across Boundaries: Collaboration in Public Services,

Basingstoke: Palgrave

Swyngedow E, F Moulaert and A Rodriguez, 2002, "Neoliberal urbanisation in Europe: Large-scale urban development projects and the New Urban Policy”, Antipode, Vol. 34 (3), pp 542-577

Syms P, 2002, Land, Development and Design, Oxford: Blackwell

Turok I, 1992, "Property-led urban regeneration: Panacea or placebo?” Environment and Planning A, Vol. 24 (3), pp 361-379 
Webber C, K Larkin, L Tochtermann, O Varley-Winter and Z Wilcox, 2010, Grand Designs? A new approach to the built environment in England's cities, London: Centre for Cities 